\title{
Gender-Related Determinants of Advanced Subclinical Atherosclerosis in Patients Undergoing Kidney Transplantation
}

\author{
Jan Pitha ${ }^{a}$ Vladimír Teplan ${ }^{\mathrm{b}}$ Marta Kalousova ${ }^{\mathrm{c}}$ Jaroslav Racek $^{\text {c, e }}$ \\ Milena Stollovab Olga Marečkováb Vera Lanskad \\ a Laboratory of Atherosclerosis Research, Department of Experimental Medicine and bepartment of Nephrology, \\ Transplant Centre, Institute for Clinical and Experimental Medicine, ' Institute of Clinical Biochemistry and \\ Laboratory Diagnostics, First Faculty of Medicine, Charles University of Prague and General University Hospital, \\ ${ }^{\mathrm{d}}$ Department of Statistics, Institute for Clinical and Experimental Medicine, Prague, and ${ }^{\mathrm{e}}$ Department of \\ Biochemistry, Charles University, Pilsen, Czech Republic
}

\section{Key Words}

Atherosclerosis, subclinical - End-stage renal disease •

Kidney transplantation - Cardiovascular risk ·

Lipid disorders • Atherogenic index of plasma •

Soluble receptor for advanced glycation end products .

Asymmetric dimethyl L-arginine

\begin{abstract}
Background: Cardiovascular disease caused by atherosclerosis remains a major cause of morbidity and mortality in patients with end-stage renal disease (ESRD). We evaluated the potential association of cardiovascular risk factors including asymmetric dimethyl L-arginine (ADMA) and the soluble receptor for advanced glycation end products (sRAGE) with preclinical atherosclerosis in patients undergoing kidney transplantation. Patients and Methods: In 92 males and 47 females undergoing the first cadaveric renal transplantation, ADMA, sRAGE and common risk factors including lipid parameters were evaluated as potential predictors of preclinical atherosclerosis defined as the Belcaro score (focused on advanced atherosclerotic changes) measured by ultrasound. Results: The prevalence of atherosclerotic changes was approximately $70 \%$ in men and women. In logistic regression, age, history of smoking, presence of diabetes mellitus, and plasma triglycerides were the strongest indepen-
\end{abstract}

dent predictors for advanced atherosclerosis in the whole group. In unadjusted analyses advanced atherosclerosis was also associated with SRAGE in men and with the atherogenic index of plasma in women. Conclusion: Apart from traditional cardiovascular risk factors, plasma triglycerides were found to be strong and independent predictors of advanced atherosclerosis in patients with ESRD. In addition, sRAGE was associated with atherosclerosis in men and the atherogenic index of plasma in women.

Copyright $\odot 2010$ S. Karger AG, Basel

\section{Introduction}

Cardiovascular disease caused by atherosclerosis remains a major cause of morbidity and mortality in patients with end-stage renal disease (ESRD). The high risk of patients with ESRD including those after kidney transplantation is undoubtedly caused by the increased prevalence of traditional cardiovascular risk factors already detected in the general population: higher age, smoking, hypertension, diabetes mellitus, obesity and dyslipid-

The study was supported by grant NR/9398-3 awarded by the Internal Grant Agency of the Czech Republic.

\section{KARGER}

Fax +41613061234 E-Mail karger@karger.ch www.karger.com
(C) 2010 S. Karger AG, Basel

$1420-4096 / 10 / 0333-0227 \$ 26.00 / 0$

Accessible online at:

www.karger.com/kbr
Jan Pitha

Laboratory of Atherosclerosis Research

Institute for Clinical and Experimental Medicine, Videnska 1952/8

CZ-140 21 Prague 4 (Czech Republic)

Tel. +420 261363 069, Fax +420 241271 574, E-Mail japi@ medicon.cz 
emias. Nevertheless, several other factors associated with renal disease could have unique effects on the initiation and acceleration of atherosclerosis. Among those most frequently discussed is the duration of hemodialysis, elevated plasma creatinine, infections and others $[1,2]$. One of recently discussed newer biomarkers indicating increased cardiovascular risk is asymmetric dimethyl L-arginine (ADMA) [3-7]. In contrast, the soluble receptor for advanced glycation end products (sRAGE) has been recognized as a potential protective factor [8-14]. These factors could be at least partly responsible for the failure of preventive strategies aimed at the prevention of cardiovascular disease, mainly hypolipemic treatment focused on LDL-cholesterol [15-17].

Studying the association of risk factors with subclinical atherosclerosis detected by ultrasound is a valuable tool for assessment of newer risk factors of atherosclerosis. This approach has already been used to evaluate the impact of various cardiovascular risk factors on carotid arteries in patients with chronic kidney diseases [18-23] including women with renal impairment [24].

Another promising approach to better individualize preventive strategies is studying gender differences. Recent recommendations for women almost do not differ from those for men [25] and thus do not fully appreciate gender differences in cardiovascular disease development and management [26]. A recent study in patients treated by hemodialysis observed greater impact of C-reactive protein and troponin $\mathrm{T}$ on cardiovascular and non-cardiovascular mortality in women [27].

In this study we analyzed potential associations of preclinical atherosclerosis in carotid and femoral arteries with traditional and newly discussed risk factors (circulating ADMA and sRAGE) in patients with ESRD undergoing kidney transplantation including potential gender differences.

\section{Patients and Methods}

The study was approved by the Human Ethical Review Committee, Institute for Clinical and Experimental Medicine, Prague, Czech Republic, and complies with the Declaration of Helsinki including current revisions and the Good Clinical Practice Guidelines. The procedures followed were in accordance with institutional guidelines. All subjects gave written informed consent before being enrolled in the study.

One hundred and thirty-nine patients (92 males and $47 \mathrm{fe}$ males) were included in the study. These patients underwent first cadaveric renal transplantation at the Transplant Centre, Institute for Clinical and Experimental Medicine, Prague, Czech Republic, between January 1, 2007 and July 12, 2008. The only exclu- sion criterion was the patient's refusal to be involved in the study (none). Biochemical measurements and collection of patient data were completed by September 31, 2009.

Patients were examined in the Clearance Laboratory, Division of Metabolism, Department of Nephrology, 1 month after renal transplantation, including blood sampling for biochemical measures. Patients were treated by a long-term triple-drug immunosuppression protocol including cyclosporin A (Neoral; Novartis) or FK506 tacrolimus (Prograf; Astellas) based regimes. The other drugs used in the management of patients were mycophenolate mofetil (Cell Cept; Roche) 1-2 g/day and steroids up to $10 \mathrm{mg} /$ day (prednisone; Zentiva, Czech Republic). In addition, all patients were treated by ACE inhibitors, angiotensin receptor blockers and statins to achieve recommended values of blood pressure and plasma lipids.

Body height, weight, and blood pressure were measured according to a standardized protocol. Body mass index was calculated as weight in kilograms divided by height in square meters. Patients with a history of current and past regular smoking were defined as ever smokers. A history of diabetes mellitus was obtained from patients' documents. Systolic and diastolic blood pressure was measured on the right arm or the arm without an arteriovenous fistula with the subject in the sitting position after at least $5 \mathrm{~min}$ at rest.

Blood samples were obtained within 2 days after renal transplantation. All patients fasted for at least $10 \mathrm{~h}$ before sampling and none of the patients suffered from acute infection at the time of the examination. Blood samples were collected into evacuated tubes with EDTA and the blood was immediately centrifuged at $3,600 \mathrm{~g}$ for $5 \mathrm{~min}$ at $20^{\circ} \mathrm{C}$.

Plasma total cholesterol and triglycerides were measured using a fully automated (Hitachi 911 autoanalyzer; Japan) enzymatic method (reagents from Hoffmann-La Roche, Basel, Switzerland). HDL-cholesterol was determined by the same method after precipitation of serum lipoproteins with sodium phosphotungstate and magnesium chloride kits. Serum LDL-cholesterol was measured by an automated method with direct determination using kit LDL-C plus from Hoffmann-La Roche. Non-HDL-cholesterol was calculated by subtracting HDL-cholesterol from total cholesterol. In addition, the atherogenic index of plasma (AIP) related to the particle size of lipoproteins was calculated as log (triglycerides/HDL-cholesterol) [28].

For ADMA quantification, the ELISA method (kit ADMA, ELISA; DLD Diagnostika GmbH, Hamburg, Germany) and Auto-EIA II microplate reader (Labsystems Oy, Espoo, Finland) were used. The concentration of sRAGE in randomly selected males $(n=43)$ and females $(n=27)$ was measured by a sandwich ELISA using standard kits (Quantikine, R\&D Systems) according to the manufacturer's protocol as described previously [8]. Albumin was measured by standard methods in the central laboratory of the institute.

\section{Ultrasound Studies}

Ultrasound studies were performed within 7 days after renal transplantation in 103 patients, within 2 months in 7 patients and in 3-6 months in 19 patients. The reasons for postponed examinations were postoperative complications and non-availability of ultrasound at the time of hospitalization. All subjects were examined in the supine position. Bilateral ultrasound assessment of the carotid and femoral arteries by Toshiba APLIO 50 XV (Tochigi, 
Japan) ultrasound system with a 7.5 - to $10-\mathrm{MHz}$ linear array transducer was performed. The carotid arteries were examined with the patient in the supine position with the neck rotated $45^{\circ}$ in the direction opposite the site being examined. The images of the common carotid arteries, bifurcation, internal and external carotid arteries were obtained. Subsequently, the femoral arteries were examined with the patient supine and images of the common femoral artery and bifurcation were obtained. All arteries were scanned by transverse and longitudinal projection. The images were digitalized and read offline (using vPACS DS software, version 6.9.25, Czech Republic) by an operator blinded to the clinical status of the patients (J.P.).

Because of the expected high prevalence of advanced atherosclerotic changes in this group of patients, the presence of preclinical atherosclerosis was defined by a semiquantitative classification - the Belcaro score. The classification by Belcaro et al. [29] has been described elsewhere. In short, this classification evaluates the degree of preclinical atherosclerosis according to the following ultrasonic findings: class I = normal, three ultrasonic layers (intima-media, adventitia, and periadventitia) were clearly separated, no disruption of the lumen-intima interface for at least $3.0 \mathrm{~cm}$, and/or initial alterations (lumen-intima interface disruption at intervals of $<0.5 \mathrm{~cm}$ ); class II = intima-media granulation, granular echogenicity of the deep, normally unechoic intimalmedial layer and/or increased intima-media thickness $(>1 \mathrm{~mm})$; class III = plaque without hemodynamic disturbance, localized wall thickening and increased density involving all ultrasonic layers, intima-media thickness $>2 \mathrm{~mm}$; class $\mathrm{IV}=$ stenotic plaque, as in class III but with hemodynamic stenosis on duplex scanning (sample volume in the center of the lumen), indicating stenosis $>50 \%$. The highest value of the Belcaro score found in the arterial system (either in carotid or femoral arteries) in each subject was used for subsequent analyses. Advanced atherosclerosis was defined as a Belcaro score of $>$ II.

Intra-observer variability was assessed by repeat measurements in 10 randomly chosen patients ( 5 men and 5 women) at a 1-week interval (J.P.). The intraclass correlation coefficient of measurements was 0.96 .

\section{Statistical Analysis}

Data are presented as the absolute and relative frequencies for categorical variables and means with standard deviations for continuous ones. Between groups comparison of continuous variables was calculated using Mann-Whitney t test. For discrete variables Pearson $\chi^{2}$ test was applied, or Yates $\chi^{2}$ test in the case of low numbers in the subgroups analyzed. Paired t test was used to analyze ADMA blood levels obtained 2 days and 3 months after transplantation. Linear regression was used to evaluate the independent predictors of preclinical atherosclerosis - the Belcaro score. All results are considered to be statistically significant at $\mathrm{p}<0.05$.

\section{Results}

Patient characteristics are shown separately for men and women in table 1 . The duration of hemodialysis, total, and HDL-cholesterol in plasma were significantly higher in women, while the prevalence of ischemic heart disease and smoking was significantly higher in men. No other significant differences between men and women were found, including the prevalence of advanced preclinical atherosclerosis in the carotid and femoral arteries, defined as a Belcaro score of >II, which was highly prevalent in both groups (fig. 1). As shown in table 1, delayed graft function after transplantation was detected in $32 \%$ of men and in $23 \%$ of women, rejection was observed in $29 \%$ of men and $20 \%$ of women. However, because all these complications occurred after blood samples were taken, and all but 5 occurred also after ultrasound studies, they were not included in the statistical analyses.

Compared to patients without advanced atherosclerosis (Belcaro $\leq \mathrm{II}$ ) patients with advanced atherosclerosis (Belcaro $>\mathrm{II})$ were older $(56.8 \pm 8.8$ vs. $41.0 \pm 10.4$ years; $\mathrm{p}<0.0001)$, had a higher prevalence of smoking (59.2 vs. $41.5 \% ; \mathrm{p}=0.017)$, a higher prevalence of diabetes mellitus (25.5 vs. $2.4 \% ; \mathrm{p}=0.006)$ and a higher prevalence of ischemic heart disease ( 0.0 vs. $21.4 \%$; $\mathrm{p}=0.005)$, higher body mass index $(27.0 \pm 4.3$ vs. $24.8 \pm 3.9 ; \mathrm{p}=0.007)$, higher plasma triglycerides $(2.81 \pm 1.76 \mathrm{vs} .2 .09 \pm 0.97 \mathrm{mmol} / \mathrm{l}$; $\mathrm{p}=0.015)$, lower plasma albumin (39.27 $\pm 4.21 \mathrm{vs} .41 .57$ $\pm 4.87 \mathrm{~g} / \mathrm{l} ; \mathrm{p}=0.006)$, and lower $\operatorname{sRAGE}(2,784.3 \pm$ $1,505.3$ vs. $4,131.9 \pm 1,052.1 \mathrm{pg} / \mathrm{ml} ; \mathrm{p}=0.003)$. No differences between patients with and without atherosclerosis were observed regarding gender, duration of hemodialysis, subsequent prevalence of delayed graft function, rejection rate, prevalence of medication and other risk factors under study.

Subsequently, we analyzed differences between patients with and without advanced atherosclerosis, separately for men and women (table 2). Men with advanced preclinical atherosclerosis were significantly older $(\mathrm{p}<$ $0.0001)$, had a higher prevalence of smoking $(\mathrm{p}=0.003)$ and diabetes mellitus ( $\mathrm{p}=0.016)$, had a higher body mass index $(p=0.014)$, lower serum albumin $(p=0.003)$, were treated more frequently by hypolipemic drugs $(p=0.005)$, and had a lower level of sRAGE ( $p=0.001)$ than men without signs of advanced atherosclerosis. Women with advanced preclinical atherosclerosis were significantly older ( $\mathrm{p}=0.0001)$, had a longer duration of hemodialysis $(\mathrm{p}=0.05)$, had higher triglycerides $(\mathrm{p}=0.019)$ and had a higher AIP ( $p=0.009)$. No other risk factors under study, including ADMA were found to be significantly different between patients with and without advanced atherosclerosis in either men or women. Because ADMA could change immediately after transplantation [30] we checked the levels of ADMA obtained from 76 patients 2 days and 3 months after transplantation. No significant change 
Table 1. Patient characteristics of men and women after kidney transplantation

\begin{tabular}{lccc}
\hline & Men $(\mathrm{n}=92)$ & Women $(\mathrm{n}=47)$ & $\mathrm{p}$ (t or $\chi^{2}$ test) \\
\hline Age, years & $52.0 \pm 12.1$ & $52.4 \pm 11.2$ & 0.960 \\
Duration of hemodialysis, months & $27.7 \pm 19.9$ & $36.3 \pm 23.1$ & 0.042 \\
Delayed graft function, $\mathrm{n}$ & $29(31.5 \%)$ & $11(23.4 \%)$ & 0.429 \\
Rejection during the first year, $\mathrm{n}$ & $25(29.1 \%)$ & $8(19.5 \%)$ & 0.286 \\
Ever smokers, $\mathrm{n}$ & $54(58.7 \%)$ & $19(40.4 \%)$ & 0.041 \\
Diabetes mellitus, $\mathrm{n}$ & $19(20.7 \%)$ & $7(14.9 \%)$ & 0.772 \\
Ischemic heart disease, $\mathrm{n}$ & $19(20.7 \%)$ & $2(4.3 \%)$ & 0.034 \\
Strokes, $\mathrm{n}$ & $2(2.2 \%)$ & $1(2.1 \%)$ & 1.000 \\
Peripheral artery disease, $\mathrm{n}$ & $6(6.5 \%)$ & $2(4.3 \%)$ & 1.000 \\
Diabetic nephropathy, $\mathrm{n}$ & $14(15.2 \%)$ & $2(4.3 \%)$ & 0.060 \\
Use of hypolipemic drugs, $\mathrm{n}$ & $33(35.9 \%)$ & $22(43.8 \%)$ & 0.212 \\
Use of antihypertensive drugs, $\mathrm{n}$ & $78(84.8 \%)$ & $41(87.2 \%)$ & 0.700 \\
Body mass index & $26.4 \pm 4.1$ & $26.1 \pm 4.7$ & 0.448 \\
Systolic blood pressure, mm Hg & $148.5 \pm 22.6$ & $88.3 \pm 2.1$ & 0.848 \\
Diastolic blood pressure, mm Hg & $88.3 \pm 12.5$ & $5.30 \pm 1.62$ & 0.886 \\
Cholesterol, mmol/l & $4.66 \pm 1.11$ & $2.50 \pm 1.4$ & 0.009 \\
Triglycerides, mmol/l & $2.66 \pm 1.7$ & $1.34 \pm 0.5$ & 0.950 \\
HDL-cholesterol, mmol/l & $1.10 \pm 0.3$ & $2.76 \pm 1.1$ & 0.0002 \\
LDL-cholesterol, mmol/l & $2.40 \pm 0.8$ & $0.23 \pm 0.27$ & 0.110 \\
Atherogenic index of plasma & $0.32 \pm 0.32$ & $3.96 \pm 1.62$ & 0.110 \\
Non-HDL-cholesterol, mmol/l & $3.56 \pm 1.13$ & $39.7 \pm 3.7$ & 0.150 \\
Albumin, g/l & $40.1 \pm 4.9$ & $0.96 \pm 0.20$ & 0.670 \\
ADMA, $\mu$ mol/l & $0.97 \pm 0.17$ & $3,528 \pm 1,706(\mathrm{n}=27)$ & 0.205 \\
sRAGE, pg/ml & $3,069 \pm 1,352(\mathrm{n}=43)$ & 0.654 \\
Belcaro $>\mathrm{II}, \mathrm{n}$ & $66(71.7 \%)$ & $32(68.1 \%)$ & \\
\hline
\end{tabular}

Unless otherwise indicated the data are expressed as means $\pm \mathrm{SD}$. Atherogenic index of plasma $=\log ($ triglycerides/HDL); non-HDL-cholesterol = total cholesterol-HDL-cholesterol; ADMA = asymmetric dimethyl Larginine; sRAGE = soluble receptors for advanced glycation end products. Body mass index calculated as weight $(\mathrm{kg}) /$ height $(\mathrm{m})^{2}$.

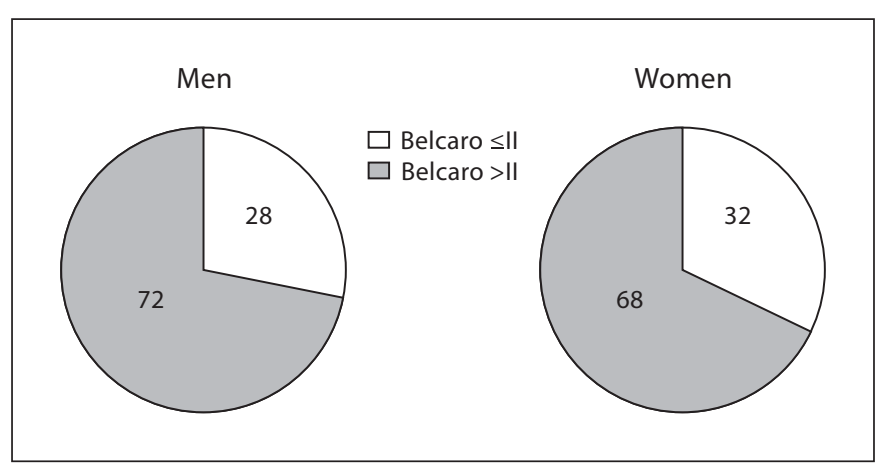

Fig. 1. Prevalence of advanced atherosclerosis expressed as Belcaro score in men and women undergoing kidney transplantation. Values are percentages. was observed $(0.96 \pm 0.20$ vs. $0.98 \pm 0.54 \mu \mathrm{mol} / \mathrm{l} ; \mathrm{p}=$ $0.67)$.

In men, sRAGE was negatively and significantly correlated only with age (correlation coefficient -0.48 ; linear regression coefficient -54.5 ; 95\% CI -87.4, -21.6). No significant association was found between sRAGE and other risk factors (body mass index, plasma lipids, plasma albumin, blood pressure, smoking and hypolipemic treatment).

In women, AIP was positively correlated with the duration of hemodialysis (correlation coefficient -0.56 ; linear regression coefficient $+0.012 ; 95 \%$ CI $0.002,0.021$ ). No significant association was found between AIP and other risk factors under study including age, smoking and hypolipemic treatment.

To assess independent predictors for the Belcaro score, we used logistic regression model comprising variables associated with the Belcaro score in previous analyses. 
Table 2. Risk factors associated with advanced atherosclerosis in men and women undergoing kidney transplantation

\begin{tabular}{llccc}
\hline & Sex & Belcaro $\leq \mathrm{II}$ & Belcaro $>$ II & $\mathrm{p}\left(\mathrm{t}\right.$ or $\chi^{2}$ test $)$ \\
\hline \multirow{2}{*}{ Age, years } & Men & $40.3 \pm 10.5(\mathrm{n}=26)$ & $56.6 \pm 9.3(\mathrm{n}=66)$ & 0.0001 \\
& Women & $42.4 \pm 10.6(\mathrm{n}=15)$ & $57.2 \pm 8.0(\mathrm{n}=32)$ & 0.0001 \\
\hline Duration of hemodialysis, months & Men & $28.05 \pm 22.1(\mathrm{n}=26)$ & $27.6 \pm 19.2(\mathrm{n}=66)$ & 0.746 \\
& Women & $26.3 \pm 17.0(\mathrm{n}=15)$ & $41.0 \pm 24.3(\mathrm{n}=32)$ & 0.051 \\
\hline Ever smokers, $\mathrm{n}$ & Men & $9(34.6 \% ; \mathrm{n}=26)$ & $45(68.2 \% ; \mathrm{n}=66)$ & 0.003 \\
& Women & $6(40.0 \% ; \mathrm{n}=15)$ & $13(40.6 \% ; \mathrm{n}=32)$ & 0.968 \\
\hline Diabetes mellitus, $\mathrm{n}$ & Men & $1(4.3 \% ; \mathrm{n}=23)$ & $18(28.6 \% ; \mathrm{n}=63)$ & 0.016 \\
& Women & $0(0 \% ; \mathrm{n}=12)$ & $7(30.4 \% ; \mathrm{n}=23)$ & 0.098 \\
\hline Use of hypolipemic drugs, $\mathrm{n}$ & Men & $3(11.5 \% ; \mathrm{n}=26)$ & $30(45.5 \% ; \mathrm{n}=66)$ & 0.005 \\
& Women & $6(40.0 \% ; \mathrm{n}=15)$ & $16(50.0 \% ; \mathrm{n}=32)$ & 0.522 \\
\hline Body mass index & Men & $24.8 \pm 3.9(\mathrm{n}=26)$ & $27.1 \pm 4.1(\mathrm{n}=66)$ & 0.014 \\
& Women & $24.7 \pm 4.1(\mathrm{n}=15)$ & $26.7 \pm 4.9(\mathrm{n}=32)$ & 0.235 \\
\hline Triglycerides, mmol/l & Men & $2.28 \pm 1.1(\mathrm{n}=26)$ & $2.81 \pm 1.9(\mathrm{n}=66)$ & 0.510 \\
& Women & $1.79 \pm 0.7(\mathrm{n}=15)$ & $2.83 \pm 1.5(\mathrm{n}=32)$ & 0.019 \\
\hline Atherogenic index of plasma & Men & $0.32 \pm 0.32(\mathrm{n}=26)$ & $0.23 \pm 0.27(\mathrm{n}=66)$ & 0.11 \\
& Women & $0.08 \pm 0.24(\mathrm{n}=15)$ & $0.30 \pm 0.26(\mathrm{n}=32)$ & 0.009 \\
\hline Albumin, g/l & Men & $42.5 \pm 5.3(\mathrm{n}=26)$ & $39.1 \pm 4.5(\mathrm{n}=66)$ & 0.003 \\
& Women & $39.9 \pm 3.7(\mathrm{n}=15)$ & $39.6 \pm 3.7(\mathrm{n}=32)$ & 0.592 \\
\hline sRAGE, pg/ml & Men & $4,080 \pm 1,201(\mathrm{n}=15)$ & $2,528 \pm 1,107(\mathrm{n}=28)$ & 0.001 \\
& Women & $4,218 \pm 802(\mathrm{n}=9)$ & $3,183 \pm 1,942(\mathrm{n}=18)$ & 0.064 \\
\hline
\end{tabular}

Unless otherwise indicated the data are expressed as means \pm SD. $\mathrm{n}=$ Total patients included in the analysis; atherogenic index of plasma $=\log$ (triglycerides/HDL); ADMA = asymmetric dimethyl L-arginine; $\mathrm{sRAGE}=$ soluble receptors for advanced glycation end products.

The following variables were put in the model: age, sex, smoking status, duration of hemodialysis, presence of diabetes mellitus, presence of hypolipemic therapy, body mass index, plasma triglycerides, AIP, plasma albumin, plasma asymmetric dimethyl L-arginine. Because of the low numbers of women with diabetes and available sRAGE, we could not include their data in the statistical model. The strongest predictors for advanced atherosclerosis were age, history of smoking, presence of diabetes mellitus and triglycerides (table 3 ).

\section{Discussion}

Based on our results, in addition to traditional cardiovascular factors such as age, history of smoking, and the presence of diabetes mellitus, higher plasma triglycerides were found to be strong and on the other risk factors independent predictors for advanced atherosclerosis.

Triglycerides and AIP expressed as log (triglycerides/ HDL-cholesterol) reflects the 'atherogenic' profile of plasma in addition to LDL-cholesterol, which is still the
Table 3. Independent predictors of advanced atherosclerosis (Belcaro score) in patients undergoing kidney transplantation

\section{OR $(95 \% \mathrm{CI})$}

Age (1 year)

$1.17(1.10,1.23)$

Ever smoking (yes/no)

Triglycerides $(1 \mathrm{mmol} / \mathrm{l})$

Diabetes mellitus (yes/no)

$3.68(1.22,11.1)$

$1.68(1.05,2.70)$

$9.34(1.02,85.4)$

Logistic regression. Data are expressed as odds ratio (95\% CI). Variables put in the model: age, sex, smoking status, duration of hemodialysis, presence/absence of diabetes mellitus, presence/absence of hypolipemic therapy, body mass index, triglycerides, atherogenic index of plasma (log (triglycerides/HDL)), albumin, asymmetric dimethyl L-arginine.

main target in most of interventional studies using hypolipemic drugs. The atherogenic profile of plasma lipoproteins is characterized by an elevated concentration of plasma triglycerides and by a predominance of small dense LDL- and low HDL-cholesterol [31]. As cardiovas- 
cular diseases remain the leading cause of death in patients with chronic kidney disease including renal transplant recipients, management of dyslipidemia is of great importance to prevent cardiovascular complications. However, in the already mentioned large prospective clinical trials the treatment focused on LDL-cholesterol failed to significantly decrease the main cardiovascular events [15-17]. Therefore, targeting treatment more aggressively also on high triglycerides and low HDL-cholesterol could be a more effective approach, especially in patients with end-stage renal failure and in women, in whom triglycerides and HDL could be more important than in men [32-34]. Looking at the data from our group, mean LDL-cholesterol was only slightly elevated above the recommended levels, undoubtedly thanks to frequent hypolipemic treatment especially in patients with advanced atherosclerosis and preexisting cardiovascular disease. However, in addition to aggressively lowering LDL, the removal of residual risk caused by higher triglycerides and low HDL-cholesterol seems to be mandatory in these patients, especially in women. In population studies it has been shown that especially younger women are more sensitive to the atherogenicity of high triglycerides and low HDL-cholesterol [33]; this fact could also be true for the population of patients with ESRD. Our results thus support the observation that renal dyslipidemia is characterized by accumulation of intact and partially metabolized triglyceride-rich lipoproteins with proatherogenic potential [35]; in addition, this potential was found to be higher only in the women of our study.

In unadjusted analyses, only age was strongly associated with advanced atherosclerosis both in men and women suffering from ESRD and undergoing kidney transplantation. While smoking, diabetes mellitus, hypolipemic treatment, body mass index, albumin and sRAGE were associated with advanced atherosclerosis in men, in women the duration of hemodialysis, triglycerides, and AIP were found to be associated with advanced atherosclerotic changes. While in men no strong association between sRAGE and all the other risk factors under study with exception of the age was found, in women AIP was also associated with the duration of hemodialysis.

As already described, lower levels of sRAGE were found to be strong predictors of cardiovascular disease in the general population [8]. In patients with chronic kidney disease the assessment of the impact of sRAGE on atherosclerosis/cardiovascular disease is complicated by its association with diabetes mellitus and/or glomerular filtration rate [9]. In a recent study, the increase in circulating sRAGE was observed in patients with chronic kid- ney disease [13]. However, the levels of sRAGE decreased after kidney transplantation during a relatively short period, with the exception of patients with early chronic vascular changes in the transplanted kidney [10]. These changes are potentially caused both by the excretion capacity of the kidneys and by the still not well understood upregulation of sRAGE to protect against the toxic effects of the RAGE ligands [12]. But even in this population, low sRAGE remained a strong predictor of cardiovascular mortality [11]. Because of the cross-sectional character of our study and possible confounding factors such as diabetes mellitus, smoking, the change in glomerular filtration rate and others, we cannot imply a cause and effect relationship regarding sRAGE and atherosclerosis. However, in patients with ESRD, well treated for traditional risk factors, circulating sRAGE could be a valuable predictor of subsequent outcomes if confirmed in prospective observational studies. An inverse correlation between sRAGE and preclinical atherosclerosis has already been described in patients with chronic kidney disease and a wide range of glomerular filtration rates [14]. The observed gender differences in our study - association of sRAGE with preclinical atherosclerosis only in men could be caused by the increased prevalence of smoking in men, and the relatively low number of women decreasing the power in this group to detect a significant statistical association.

The absence of an association between blood pressure and advanced atherosclerosis was very probably caused by the antihypertensive treatment of nearly all the patients (table 1).

We did not find any association between ADMA and preclinical atherosclerosis, although increased ADMA levels correlated strongly with the severity of the atherosclerotic disease in previous studies and a strong correlation was found with intima-media thickness of the carotid arteries [36]. This discrepancy could be partly explained by a methodological approach: in our study we focused on more advanced stages of atherosclerosis. Therefore, ADMA could be more related to less advanced atherosclerotic changes and their progression and less related to the already developed advanced atherosclerotic plaques. In addition, we did not find any strong correlation between ADMA levels and other risk factors under study. After reviewing the available literature, in patients with ESRD we found the plasma concentration of ADMA to be mostly in the range of $1-2.5 \mu \mathrm{mol} / \mathrm{l}$. ADMA levels in our population were at the lower border of this range (around $1 \mu \mathrm{mol} / \mathrm{l}$ ). The cause for this finding could be intensive treatment with cardiovascular drugs, which 
was rather high in our population before transplantation (antihypertensive drugs in $80 \%$ and lipid-lowering drugs in $40 \%$ of patients). The variation in ADMA levels immediately after transplantation as already reported [30] could also be a reason for false-negative results regarding the correlation between ADMA levels and cardiovascular risk factors under study. However, we did not find any significant difference between ADMA levels obtained 2 days and 3 months after transplantation in 76 patients. Therefore, the different results observed in our study could rather be caused by a different population of patients of different ethnic origin and with different status/ treatment before transplantation (inclusion of only living donors by Yilmaz et al. [30]). In addition, the use of different laboratory methodologies could be also of importance.

In general, strong evidence exists that cardiovascular risk factors and their impact could qualitatively and quantitatively differ between men and women with ESRD [27]. Similar evidence was observed in our study: predictors of advanced atherosclerosis between men and women were different, despite the similar age of both groups. A surprising finding was the association between the duration of hemodialysis and advanced atherosclerotic changes in women only; in addition, in women, the duration of hemodialysis was strongly associated with AIP. However, whether the deleterious effects of hemodialysis can be mediated through impaired lipid metabolism in women could not be established based on our data, and longitudinal studies should address this question.

Another important finding in our study was the very high prevalence of advanced stages of atherosclerosis in carotid and femoral arteries, putting in question the fre- quently used intima-media thickness measurements in this high-risk population. In addition, the prevalence of advanced atherosclerosis was the same in men and women of similar age in our study, despite the fact that in the general population women develop cardiovascular disease 10-20 years later than men.

The main limitation of our study is its cross-sectional design which did not allow us to assess the cause and effect relationship. Also the relatively low number of women could be a cause of the observed differences between both genders in statistical associations of different cardiovascular risk factors with advanced atherosclerosis. The strengths of our study are the specific population of patients with ESRD undergoing kidney transplantation, the gender-oriented approach, and the assessment of not only traditional but also newly discussed risk factors, including newer lipid profile parameters, and the assessment of their association with advanced atherosclerosis not only in carotid but also in femoral arteries.

\section{Conclusion}

Apart from traditional cardiovascular risk factors such as age, smoking and diabetes mellitus, plasma triglycerides were found to be strong and independent predictors of advanced atherosclerosis in men and women with ESRD undergoing renal transplantation and treated frequently with antihypertensive and hypolipemic drugs. Based on our results, sRAGE in men and AIP in women deserve attention as potential newer risk factors for atherosclerosis.

\section{References}

1 de Mattos AM, Prather J, Olyaei AJ, Shibagaki Y, Keith DS, Mori M, Norman DJ, Becker $\mathrm{T}$ : Cardiovascular events following renal transplantation: role of traditional and transplant - specific risk factors. Kidney Int 2006;70:757-764.

$\checkmark 2$ Fazelzadeh A, Mehdizadeh AR, Ostovan MA, Raiss-Jalali GA: Predictors of cardiovascular events and associated mortality of kidney transplant recipients. Transplant Proc 2006;38:509-511.

$\checkmark 3$ Boger RH: Association of asymmetric dimethylarginine and endothelial dysfunction. Clin Chem Lab Med 2003;41:14671472 .
-4 Scalera F, Borlak J, Beckmann B, MartensLobenhoffer J, Thum T, Täger M, BodeBöger SM: Endogenous nitric oxide synthesis inhibitor asymmetric dimethyl L-arginine accelerates endothelial cell senescence. Arterioscler Thromb Vasc Biol 2004;24:18161822.

5 Fliser D: Asymmetric dimethylarginine (ADMA): the silent transition from an 'uremic toxin' to a global cardiovascular risk molecule. Eur J Clin Invest 2005;35:71-79.

-6 Teplan V, Schück O, Racek J, Lecian D, Haluzik M, Kudla M, Vitko S: Asymmetric dimethyl arginine in obesity after renal transplantation. J Ren Nutr 2008;18:513520 .
7 Mallamaci F, Zoccali C: Clinical implications of elevated asymmetric dimethylarginine in chronic kidney disease and end-stage renal disease. J Ren Nutr 2009;19:25-28.

-8 Falcone C, Emanuele E, D’Angelo A, Buzzi MP, Belvito C, Cuccia M, Geroldi D: Plasma levels of soluble receptor for advanced glycation end products and coronary artery disease in nondiabetic men. Arterioscler Thromb Vasc Biol 2005;25:1032-1037.

9 Kalousová M, Hodková M, Kazderová M, Fialová J, Tesar V, Dusilová-Sulková S, Zima T: Soluble receptor for advanced glycation end products in patients with decreased renal function. Am J Kidney Dis 2006;47:406-411. 
\10 Kalousová M, Bartosová K, Zima T, Skibová J, Teplan V, Viklický O: Pregnancy-associated plasma protein $\mathrm{A}$ and soluble receptor for advanced glycation end products after kidney transplantation. Kidney Blood Press Res 2007;30:31-37.

- 11 Koyama H, Shoji T, Fukumoto S, Shinohara K, Shoji T, Emoto M, Mori K, Tahara H, Ishimura E, Kakiya R, Tabata T, Yamamoto $H$, Nishizawa Y: Low circulating endogenous secretory receptor for AGEs predicts cardiovascular mortality in patients with end-stage renal disease. Arterioscler Thromb Vasc Biol 2007:27:147-153.

12 Koyama H, Yamamoto H, Nishizawa Y: Endogenous secretory RAGE as a novel biomarker for metabolic syndrome and cardiovascular diseases. Biomark Insights 2007;2: 331-339.

13 Kanková K, Kalousová M, Hertlová M, Krusová D, Olsovský J, Zima T: Soluble RAGE, diabetic nephropathy and genetic variability in the AGER gene. Arch Physiol Biochem 2008;114:111-119.

- 14 Basta G, Leonardis D, Mallamaci F, Cutrupi S, Pizzini P, Gaetano L, Tripepi R, Tripepi G, De Caterina R, Zoccali C: Circulating soluble receptor of advanced glycation end product inversely correlates with atherosclerosis in patients with chronic kidney disease. Kidney Int 2010;77:225-231.

15 Holdaas H, Fellström B, Jardine AG, Holme I, Nyberg G, Fauchald P, Grönhagen-Riska C, Madsen S, Neumayer HH, Cole E, Maes B, Ambühl P, Olsson AG, Hartmann A, Solbu DO, Pedersen TR; Assessment of LEscol in Renal Transplantation (ALERT) Study Investigators: Effect of fluvastatin on cardiac outcomes in renal transplant recipients: a multicentre, randomised, placebo-controlled trial. Lancet 2003;361:2024-2031.

-16 Wanner C, Krane V, März W, Olschewski M, Mann JF, Ruf G, Ritz E; German Diabetes and Dialysis Study Investigators: Atorvastatin in patients with type 2 diabetes mellitus undergoing hemodialysis. N Engl J Med 2005;353:238-248.

- 17 Fellström BC, Jardine AG, Schmieder RE, Holdaas H, Bannister K, Beutler J, Chae DW, Chevaile A, Cobbe SM, Grönhagen-Riska C, De Lima JJ, Lins R, Mayer G, McMahon AW, Parving HH, Remuzzi G, Samuelsson O, Sonkodi S, Sci D, Süleymanlar G, Tsakiris D, Tesar V, Todorov V, Wiecek A, Wüthrich RP, Gottlow M, Johnsson E, Zannad F; AURORA Study Group: Rosuvastatin and cardiovascular events in patients undergoing haemodialysis. N Engl J Med 2009;360:1395-1407.

18 Brzosko S, Hryszko T, Lebkowska U, Malyszko J, Malyszko JS, Mysliwiec M: Plasma tissue-type plasminogen activator, fibrinogen, and time on dialysis prior to transplantation are related to carotid intima media thickness in renal transplant recipients. Transplant Proc 2003;35:2931-2934.

-19 Stompór T, Kraśniak A, Sułowicz W, Dembińska-Kieć A, Janda K, Wójcik K, Ta- bor B, Kowalczyk-Michałek ME, Zdzienicka A, Janusz-Grzybowska E: Changes in common carotid artery intima-media thickness over 1 year in patients on peritoneal dialysis. Nephrol Dial Transplant 2005;20:404-412.

20 Genís BB, Granada ML, Alonso N, Lauzurica R, Jiménez JA, Barluenga E, Homs M, Pastor MC, Salinas I, Quintero JC, Sanmartí A, Romero R: Ghrelin, glucose homeostasis, and carotid intima media thickness in kidney transplantation. Transplantation 2007; 84:1248-1254

21 Nafar M, Khatami F, Kardavani B, Farjad R, Pour-Reza-Gholi F, Firoozan A: Atherosclerosis after kidney transplantation: changes of intima-media thickness of carotids during early posttransplant period. Urol J 2007;4: 105-110.

22 Alvarez A, Fernandez J, Porrini E, Delgado P, Pitti S, Vega MJ, González-Posada JM, Rodríguez A, Pérez L, Marrero D, Luis D, Velázquez S, Hernández D, Salido E, Torres A: Carotid atheromatosis in nondiabetic renal transplant recipients: the role of prediabetic glucose homeostasis alterations. Transplantation 2007;84:870-875.

23 Buyukhatipoglu H, Tiryaki O, Tahta K, Usalan C: Inflammation as a risk factor for carotid intimal-medial thickening, a measure of subclinical atherosclerosis in haemodialysis patients: the role of chlamydia and cytomegalovirus infection. Nephrology (Carlton) $2007 ; 12: 25-32$.

24 Ishizaka Y, Ishizaka N, Tani M, Toda A, Toda E-I, Koike K, Yamakado M: Relationship between albuminuria, low eGFR, and carotid atherosclerosis in Japanese women. Kidney Blood Press Res 2008;31:164-170.

25 Mosca L, Banka CL, Benjamin EJ, Berra K, Bushnell C, Dolor RJ, Ganiats TG, Gomes AS, Gornik HL, Gracia C, Gulati M, Haan CK, Judelson DR, Keenan N, Kelepouris E, Michos ED, Newby LK, Oparil S, Ouyang P, Oz MC, Petitti D, Pinn VW, Redberg RF, Scott R, Sherif K, Smith SC Jr, Sopko G, Steinhorn RH, Stone NJ, Taubert KA, Todd BA, Urbina E, Wenger NK; Expert Panel/ Writing Group: American Academy of Physician Assistants; American Association for Clinical Chemistry; American Association of Cardiovascular and Pulmonary Rehabilitation; American College of Chest Physicians; American College of Emergency Physicians; American Diabetes Association American Geriatrics Society; American Society for Preventive Cardiology; American Society of Echocardiography; American Society of Nuclear Cardiology; Association of Women's Health, Obstetric and Neonatal Nurses; Global Alliance for Women's Health; Mended Hearts, Inc; National Black Nurses Association; National Black Women's Health Imperative; National Women's Health Resource Center; North American Menopause Society; Partnership for Gender-Specific Medicine at Columbia University; Preventive Cardiovascular Nurses As- sociation; Society for Vascular Medicine and Biology; Society for Women's Health Research; Society of Geriatric Cardiology; Women in Thoracic Surgery; WomenHeart: the National Coalition for Women with Heart Disease: Evidence-based guidelines for cardiovascular disease prevention in women: 2007 update. J Am Coll Cardiol 2007;49:1230-1250.

-26 Mendelsohn ME, Karas RH: Molecular and cellular basis of cardiovascular gender differences. Science 2005;308:1583-1587.

27 Hocher B, Kalk P, Godes M, Liefeldt L, Ziebig R, Stasch JP, Quaschning T, Pfab T: Genderdependent impact of risk factors for cardiovascular and non-cardiovascular mortality in end-stage renal disease patients on haemodialysis. Kidney Blood Press Res 2008;31: 360-366.

28 Dobiasova M, Frohlich J: The plasma parameter $\log$ (TG/HDL-C) as an atherogenic index: correlation with lipoprotein particle size and esterification rate in apoB-lipoprotein-depleted plasma (FER(HDL)). Clin Biochem 2001;34:583-588.

29 Belcaro G, Nicolaides AN, Laurora G, Cesarone MR, de Sanctis M, Incandela LA: Ultrasound morphology classification of the arterial wall and cardiovascular events in a 6-year follow-up study. Arterioscler Thromb Vasc Biol 1996;16:851-856

- 30 Yilmaz MI, Saglam M, Caglar K, Cakir E, Ozgurtas T, Sonmez A, Eyileten T, Yenicesu M, Acikel C, Oguz Y, Ozcan O, Bozlar U, Erbil K, Aslan I, Vural A: Endothelial functions improve with decrease in asymmetric dimethylarginine (ADMA) levels after renal transplantation. Transplantation 2005;80: 1660-1666.

-31 Dobiasova M, Raslova K, Rauchova H, Vohnout B, Ptackova K, Frohlich J: Atherogenic lipoprotein profile in families with and without history of early myocardial infarction. Physiol Res 2001;50:1-8.

32 Rich-Edwards JW, Manson JE, Hennekens $\mathrm{CH}$, Buring JE: The primary prevention of coronary heart disease in women. N Engl J Med 1995;332:1758-1766.

33 LaRosa JC: Triglycerides and coronary risk in women and the elderly. Arch Intern Med 1997;157:961-968.

- 34 McNamara JR, Shah PK, Nakajima K, Cupples LA, Wilson PW, Ordovas JM, Schaefer EJ: Remnant-like particle (RLP) cholesterol is an independent cardiovascular disease risk factor in women: results from the Framingham Heart Study. Atherosclerosis 2001; 154:229-236.

-35 Attman PO, Samuelsson O: Dyslipidemia of kidney disease. Curr Opin Lipidol 2009;20: 293-299.

- 36 Zoccali C, Benedetto FA, Maas R, Mallamaci F, Tripepi G, Malatino LS, Böger R; CREED Investigators: Asymmetric dimethylarginine, C-reactive protein, and carotid intimamedia thickness in end-stage renal disease. J Am Soc Nephrol 2002;13:490-496. 